\title{
DESENVOLVIMENTO DO JOGO DIGITAL JARDIM DO FERRO PARA PREVENÇÃO DA ANEMIA FERROPRIVA
}

\section{Nícholas Doviggi Meyer; Gabriel Rodrigues Felipetto²; Marianne Machado; Rejane Costa Beber ; Alexandre De Oliveira Zamberlan ${ }^{5}$; Franceliane Jobim Benedetti ${ }^{6}$}

\section{RESUMO}

Este trabalho teve como objetivo desenvolver um jogo digital educacional para a faixa etária de crianças entre quatro a seis anos de idade e que aborda sobre a prevenção à anemia. Foi desenvolvido um jogo com três fases diferentes, a primeira introduzindo as mecânicas, a segunda voltada para puzzles, e a terceira voltada para desafios de plataforma. Ele foi criado na Engine Unity, inteiramente 2D, com arte original e trilhas sonoras baixadas de fontes no copyright. Foi necessário uma equipe composta por um lead designer, uma artista e um programador para a construção do jogo e uma nutricionista e uma pediatra para montar e consolidar o conteúdo. $\mathrm{O}$ jogo foi concluído e está em processo de registro. Espera-se que o produto possa auxiliar no ensino de boas escolhas alimentares para a prevenção de anemia.

Palavras-chave: Aplicativos móveis, Educação alimentar e nutricional, Software, Tecnologia.

Eixo Temático: Tecnologia, Inovação e Desenvolvimento Sustentável (TIDS).

\section{INTRODUÇÃO}

De acordo com a OMS (1975), a anemia é caracterizada como um estado em que a concentração de hemoglobina do sangue está abaixo do normal em consequência da carência de um ou mais nutrientes essenciais, não importando a origem dessa carência. Também é afirmado que a carência de ferro é a que ocorre mais frequentemente e tem prevalência em crianças. A anemia ferropriva é quando esta ocorre devido a carência de ferro em relação às necessidades fisiológicas.

As crianças por estarem em um período de desenvolvimento têm uma demanda maior por ferro (ZAVETA, 2017). Caso essa demanda não seja suprida, há chances de desenvolverem anemia ferropriva. Acomete todos os estratos sociais, 
podendo ser maior em populações com maior vulnerabilidade social, afetando principalmente crianças menores de cinco anos (WHO, 2017; MCLEAN et al., 2009;).

Como afirma Moreira (2017), ofertar atividades lúdicas em escolas é uma excelente forma de introduzir o diálogo sobre algum determinado conteúdo, o que facilita o seu ensino por um profissional. Jogos digitais são um excelente recurso lúdico e que se aplicado corretamente consegue transmitir uma ideia mesmo que não completamente explícita.

Para auxiliar na prevenção da anemia ferropriva, este trabalho tem por objetivo produzir um jogo digital com a intenção de conscientizar o público infantil e familiares sobre a importância da ingestão de alimentos ricos em ferro, já que este mostra-se uma ótima atividade lúdica.

\section{METODOLOGIA}

Este trabalho é uma pesquisa aplicada e faz parte de um projeto denominado "Jardim do Ferro: Jogo Digital como Ferramenta para a Prevenção da Anemia Ferropriva na Infância".

Foi projetado um jogo digital com três fases distintas para o público-alvo de crianças entre quatro a seis anos de idade. Cada fase tem um intuito diferente de game feel (SWINK, 2008) para o jogador. Além disso, foi planejado um quizz para que os pais ou responsáveis das crianças respondam para testar e aprimorar seus conhecimentos sobre a absorção de ferro e anemia.

Para o desenvolvimento do jogo foi necessário montar uma equipe multidisciplinar constituída por um lead designer, uma artista, um programador, uma nutricionista e uma pediatra.

$\mathrm{O}$ jogo é um plataformer 2D e foi desenvolvido na engine Unity. A gerência do projeto foi realizada na plataforma HacknPlan, a arte desenhada no software Procreate e vetorizada no Adobe llustrator. A metodologia escolhida foi a de Chandler (2009), que consiste em quatro etapas cíclicas. A etapa pré-produção é o 
momento em que se define o escopo do projeto, plataforma de publicação, escolha da temática, estilo de jogo, público-alvo, levantamento da equipe, entre outros. $\mathrm{Na}$ segunda etapa, a produção é onde o jogo é de fato produzido, ou seja, é desenvolvida a arte, a programação, o game e level design, o sound design e tudo o que for necessário para o jogo. A etapa de testes é o momento em que se valida o que foi realizado até o momento, se está de acordo com o que foi planejado e se possui presença ou não de bugs. Por fim há a etapa de finalização, onde é realizado o levantamento de pontos fortes e pontos fracos do projeto para serem reutilizados ou evitados em projetos futuros, ou seja, é o post-mortem do projeto.

\section{RESULTADOS E DISCUSSÕES}

Foi desenvolvido um jogo digital para a plataforma Android com três fases diferentes. A primeira fase é apenas introdutória, onde é apresentada as principais mecânicas para o jogador. Na segunda fase é introduzido alguns puzzles, então é uma fase que requer um pouco mais de pensamento lógico. E por fim, a terceira fase é composta por múltiplos desafios de plataforma em sequência, ou seja, uma fase de ação. Cada fase consegue trazer uma sensação diferente de gameplay, evitando cair na repetição.

O game design do jogo foi pensado para que o jogador absorva o conteúdo de uma forma natural por associação, ou seja, no jogo alimentos ricos em ferro os concederão pontuação ou serão seus aliados (Figura 1). Também foram apresentados alguns alimentos como vilões (Figura 1), e que o jogador poderá associar como alimentos não adequados. O jogador pode associar esses benefícios e malefícios no jogo com a vida real, assim que for ofertado estes alimentos para ele. Acredita-se que essa possa ser uma ótima maneira de cumprir com o propósito educativo do produto. 

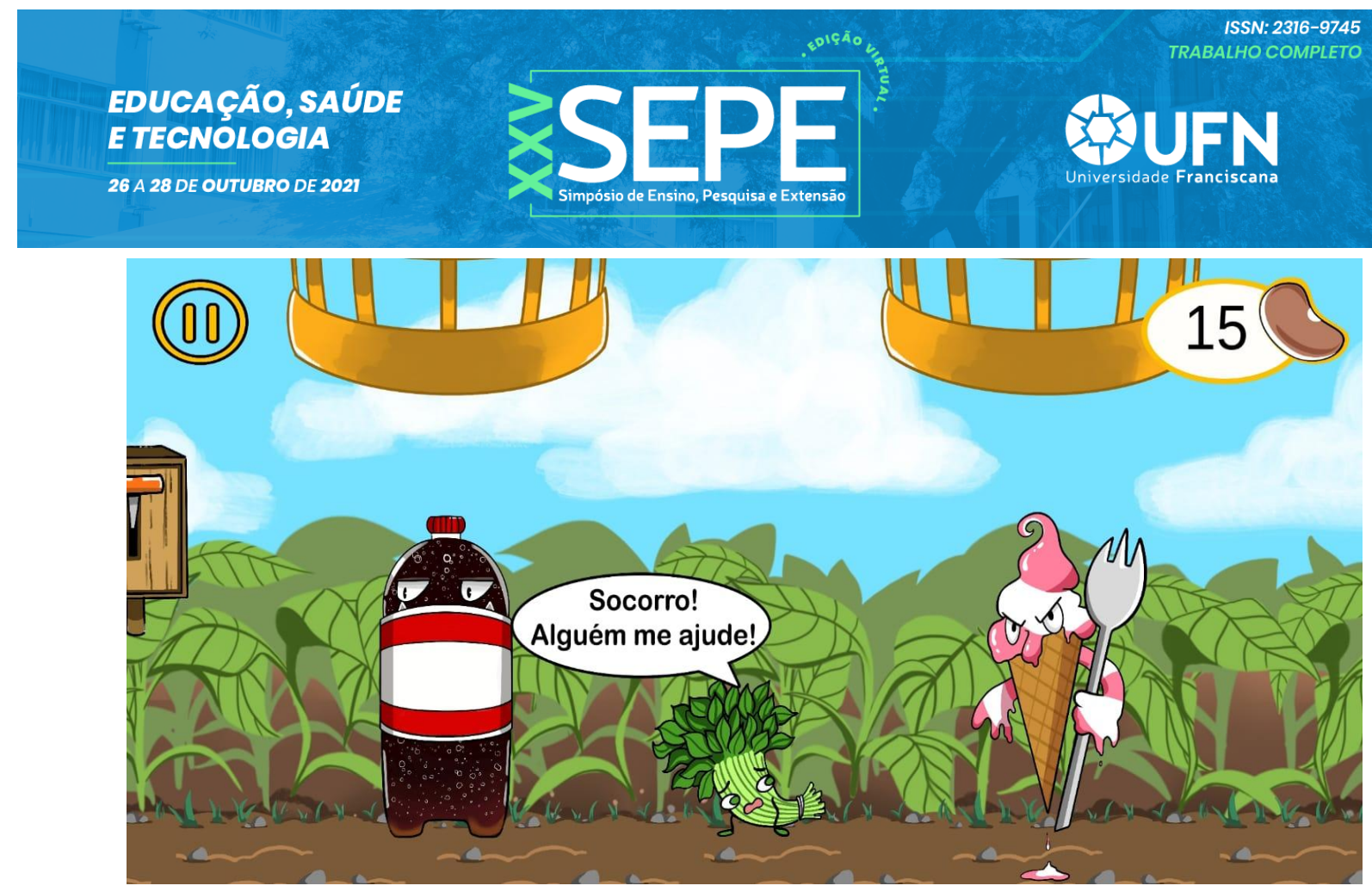

Figura 1: Espinafre sendo ameaçado por um sorvete e um refrigerante.

São cinco personagens com características físicas distintas (Figura 2) para que o jogador escolha o que gostar mais ou o que mais se identifica. Esses personagens se assemelham às crianças do público-alvo e são de diferentes sexos e etnias.

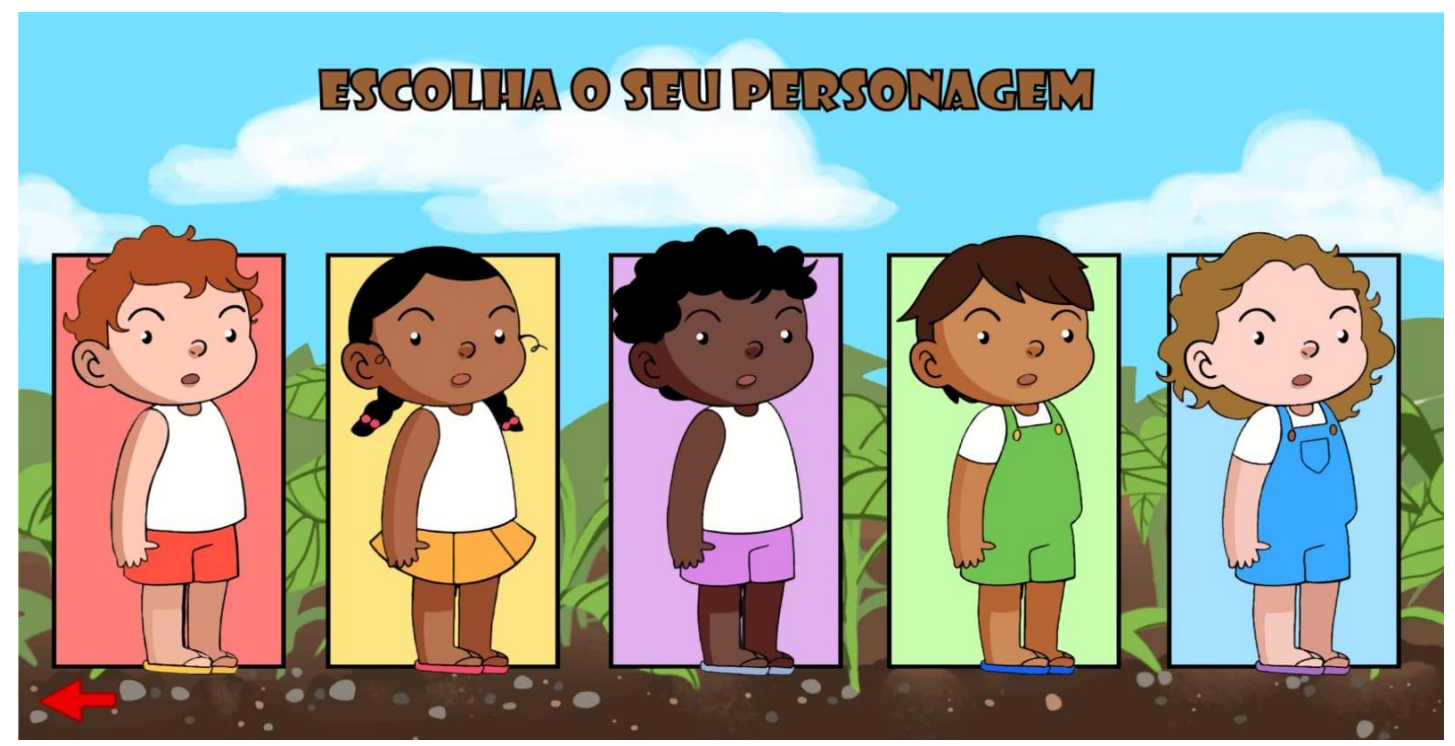

Figura 2: Seleção de personagens.

O jogo é um plataformer com elementos de puzzle. As mecânicas do jogo consistem em: pular, balançar na corda, ativar alavancas, mover plataformas móveis, subir escadas, girar manivelas, colecionar feijões e ativar buffs e debuffs. 
Cada uma dessas ações possuirá um feedback ou objetivo, como abrir uma porta ou evitar um obstáculo. Caso o personagem caia em algum obstáculo, ele será levado para o checkpoint anterior, como uma espécie de morte e renascimento instantâneo. O jogo não possui nenhum tipo de game over para evitar a frustração do jogador (KOSTER, 2013).

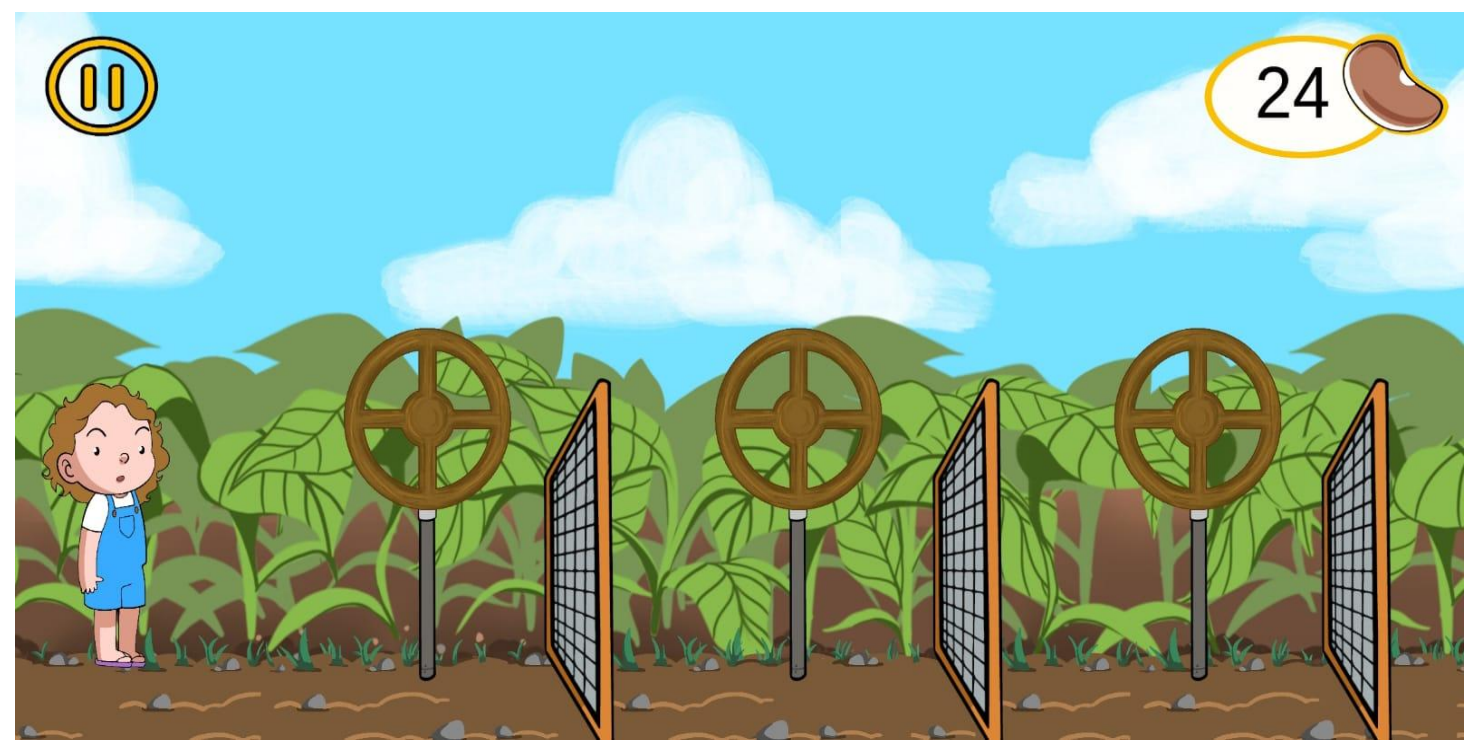

Figura 3: exemplo de puzzle onde o jogador deverá levantar os três obstáculos para prosseguir na fase.

Um dos buffs é quando o jogador coleta uma laranja. Ao coletá-la, os próximos feijões que forem coletados terão seu valor dobrado, o que simboliza a vitamina C da laranja ajudando na absorção do ferro do feijão. Também há um debuff, que se o jogador coletar um leite e após isso coletar feijões, o valor destes feijões será reduzido pela metade e o personagem ficará mais lento, o que simboliza o cálcio do leite dificultando a absorção de ferro dos feijões. Mas caso o jogador colete o leite mas não pegue feijões, o personagem irá ficar mais rápido, o que simboliza que o leite isoladamente é um bom alimento.

Após o jogador concluir as três fases, ele devolverá todos os feijões que ele coletou pelo caminho para o "Rei Feijão" e para a "Rainha Carne". Esses feijões serão a pontuação final do jogador e mostrará como foi o seu desempenho (Figura 4). Essa pontuação pode estimular que o jogador repita a jogatina para obter uma pontuação maior (ROGERS, 2013). 

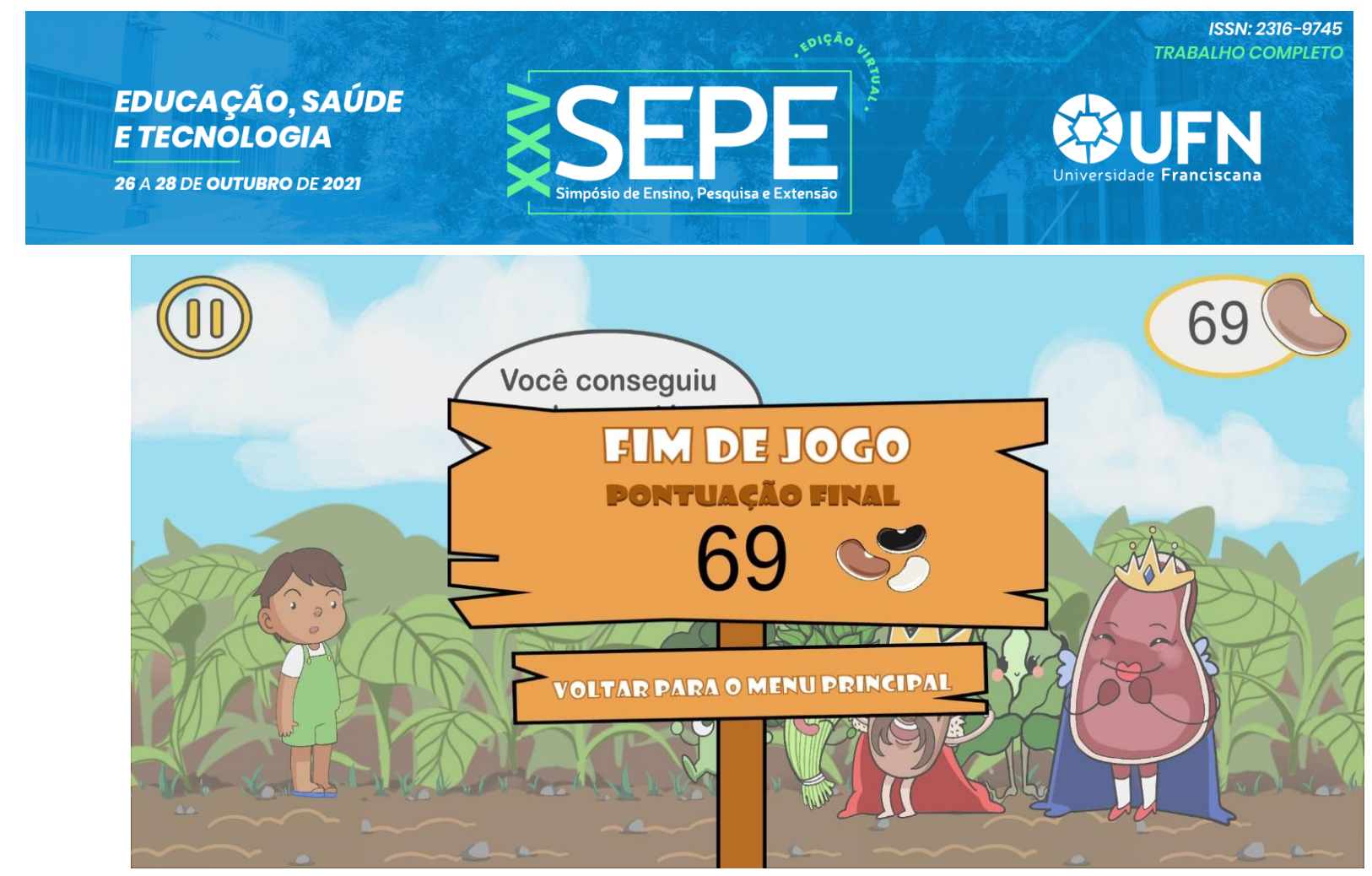

Figura 4: Pontuação final.

Também foi desenvolvido o quizz para pais e responsáveis e é encontrado logo abaixo do botão de jogar na tela principal do jogo (Figura 5). Serão realizadas cinco afirmações e o jogador terá que responder se ela é verdadeira ou falsa. Após ser respondida, aparecerá uma breve explicação do porquê esta afirmação ser correta ou errada (Figura 6). O quizz também conta com a opção de"não sei” para pular a questão. O jogador poderá pular até três questões. Ao finalizar o jogo, é revelado quantas questões o jogador acertou.

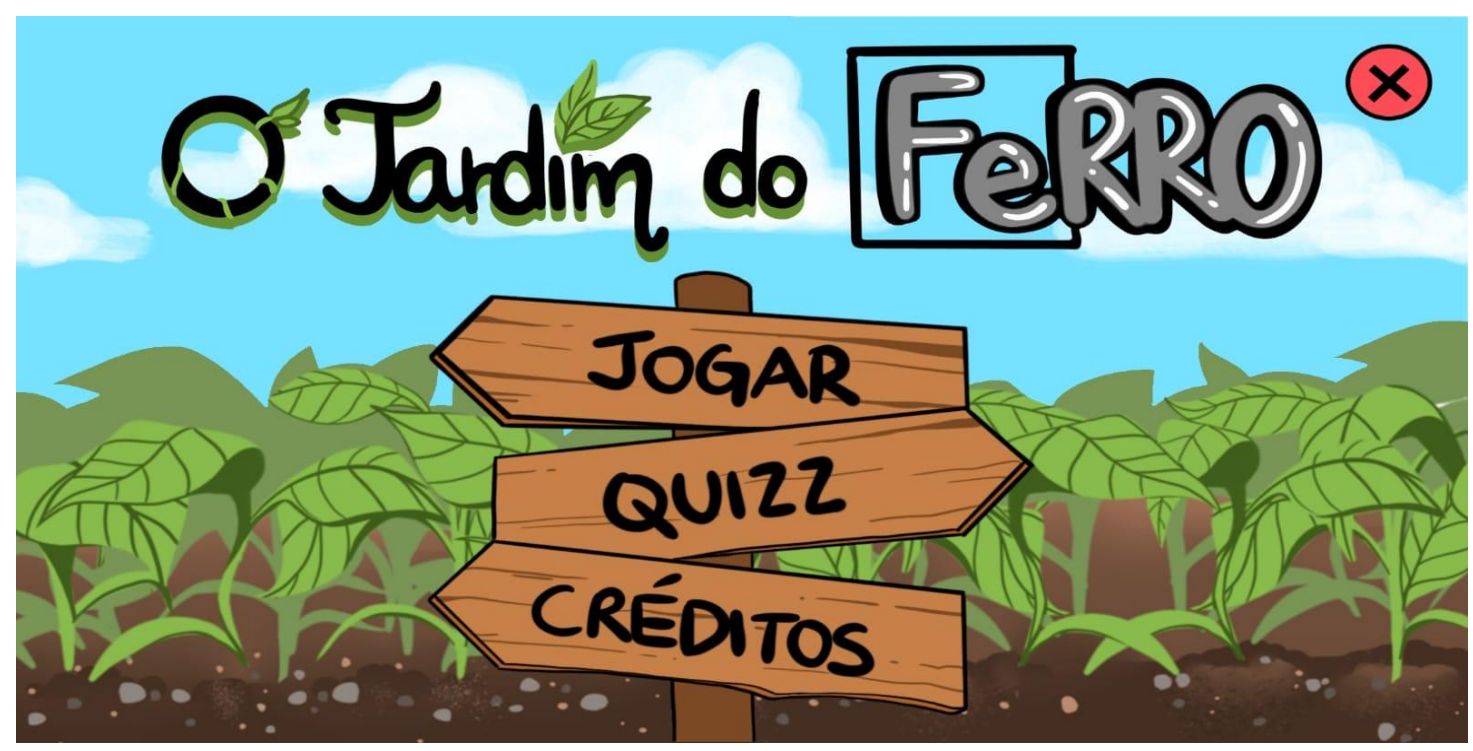

Figura 5: Tela inicial. 

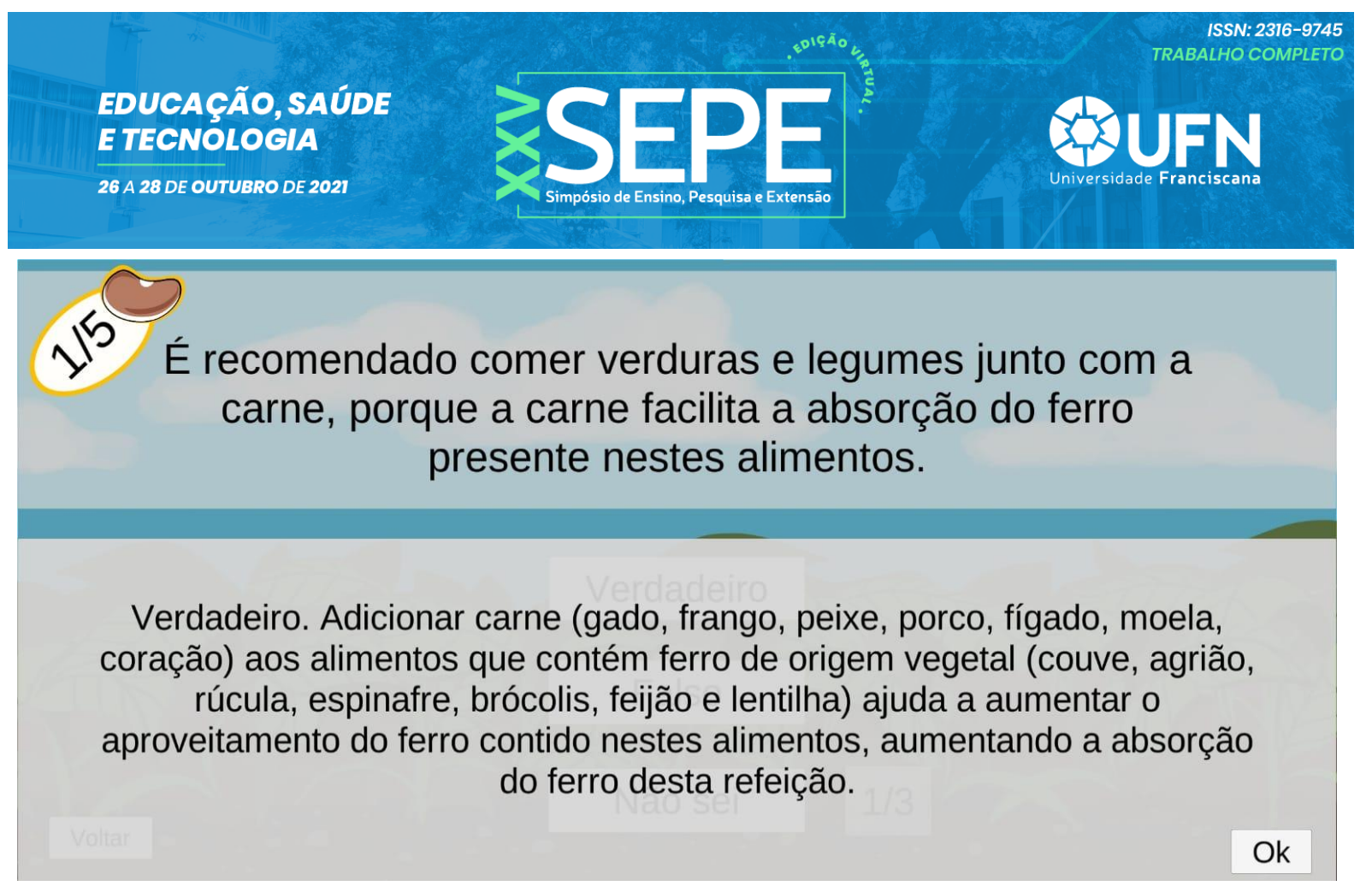

Figura 6: Justificativa do quizz.

O programa de computador intitulado "Jardim do Ferro", está em processo de registro no Instituto Nacional de Propriedade Industrial-INPI através da Agência de Inovação- UFN.

\section{CONCLUSÃO}

Acredita-se que o jogador poderá associar os alimentos ricos em ferro do jogo como alimentos bons de serem ingeridos na vida real, por estes possuírem semblantes amistosos, serem seus companheiros dentro do jogo e ajudá-los é parte do objetivo principal do jogo. Além disto, estes alimentos também fazem parte de sua pontuação e o jogador pode associar que quanto mais ingeri-los, melhor. Por outro lado, o jogador também poderá querer evitar os alimentos inadequados, já que estes possuem características agressivas e com o intuito de fazer o jogador associá-los com vilões.

O jogo foi concluído e aplicados playtests (processo pelo qual um game designer ou um jogador do público-alvo testa um novo jogo para detectar bugs e falhas antes de colocá-lo no mercado) para diversos públicos, inclusive para o público-alvo. O quizz foi aplicado para indivíduos adultos e o jogo para crianças menores de dez anos e aparentemente cumpre com seu propósito educativo, já que os adultos jogaram o quizz várias vezes e as crianças concluíram o jogo e jogaram 


\section{QSUFN}

novamente para superar sua pontuação e ajudar os NPC's novamente.

Posteriormente o jogo será disponibilizado para escolas, abrangendo professores, alunos e responsáveis. Espera-se que o produto possa auxiliar no ensino de boas escolhas alimentares para a prevenção de anemia.

\section{AGRADECIMENTOS}

Ao Conselho Nacional de Desenvolvimento Científico e Tecnológico (CNPq), pela bolsa PIBITI CNPq e a Agência de Inovação Tecnológica da Universidade Franciscana (UFN).

\section{REFERÊNCIAS}

CHANDLER, Heather. Manual de produção de jogos digitais. Bookman Editora, 2009.

KOSTER, Raph. Theory of fun for game design. " O'Reilly Media, Inc.", 2013. MOREIRA SILVA DE MEIRELLES, Rosane et al. Jogos sobre educação em saúde: limites e possibilidades. Enseñanza de las ciencias, n. Extra, p. 5079-5085, 2017.

MCLEAN, E., COGSWELLI, M., EGLI, I., WOJDYLA, D. \& de BENOIST, B. Worldwide prevalence of anaemia, WHO Vitamin and Mineral Nutrition Information System 1993-2005. Public Health Nutr. 12, 444-454 (2009).

MOREIRA SILVA DE MEIRELLES, Rosane et al. Jogos sobre educação em saúde: limites e possibilidades. Enseñanza de las ciencias, n. Extra, p. 5079-5085, 2017. 
ORGANIZAÇÃO MUNDIAL DE SAÚDE. Lucha contra la anemia nutricional, especialmente contra la carência de hierro: Informe ADI/OIEA/OMS. Série de Informes Técnicos, 580. Genebra: OMS, 1975.

ROGERS, Scott. LEVEL UP: um guia para o design de grandes jogos. São Paulo - SP: Blucher, 2013.

SWINK, Steve. Game feel: a game designer's guide to virtual sensation. CRC Press, 2008.

WORLD HEALTH ORGANIZATION. Nutritional anaemias: tools for effective prevention and control. Geneva: World Health Organization; 2017.

ZAVALETA, Nelly. Anemia infantil: retos y oportunidades al 2021. Rev Peru Med Exp Salud Publica. v. 34, n.4, Jul-Sep, 2017. 